\title{
DE LOS TERRITORIOS PROTOURBANOS A LOS TERRITORIOS URBANOS: CIELO DE SERPIENTES DE ANTONIO GIL ${ }^{1}$
}

\author{
FROM PROTO-URBAN TERRITORIES TO URBAN TERRITORIES: \\ CIELO DE SERPIENTES $B Y$ ANTONIO GIL
}

\author{
Eduardo Barraza Jara ${ }^{1}$ y Nelson Vergara Muñoz ${ }^{2}$
}

\begin{abstract}
Con todos sus niveles, estratos o subsuelos de sentidos, el territorio es un escorzo de mundos articulados y situados en una cultura. Así, cuando el hombre marca o demarca un territorio delimita un locus mayor o menor según la representación y la conciencia que tenga de los horizontes de sus mundos, en rigor, cotidianos, familiares o extraños. De aquí la notable conexión del territorio con la identidad, personal o colectiva, y su manifestación en la memoria, en la imaginación y en el discurso como es el caso de Cielo de serpientes de Antonio Gil. Según nuestro análisis, en esta novela el hallazgo de un niño inca consagrado en las estribaciones andinas y protourbanas del cerro El Plomo provoca en el aquí y ahora de la territorialidad urbana de la metrópoli un discurso reactivo que subvierte las frágiles junturas de los distintos espacios y estamentos que la capital santiaguina se ha dado a la fecha. Por esta vía, esta novela discute narrativamente los segmentos y estatus del saber y del poder, de modo que polemiza con la noción de territorio y con las formas de saberes culturales y populares que en él se manifiestan. Por lo mismo, en este texto el espacio resulta una dimensionalidad vivida y apropiada por cada sujeto y no transable ni por otras prácticas ni por otros sueños.
\end{abstract}

Palabras claves: rituales incas, territorialidad andina, territorio urbano, novela chilena.

Territory, with all its levels, strata or subsoil layers of meaning, is a glimpse of worlds articulated and placed in a culture. When man marks or demarcates a territory, he defines a locus which varies according to the representation and consciousness he has of the horizons of his everyday, familial or strange worlds. Hence the strong connection of territory with personal or collective identity, and its manifestation in memory, imagination and discourse as illustrated in Cielo de Serpientes by Antonio Gil. In this novel, according to our analysis, the finding of a child sacrificed following the Inca rituals in the Cerro El Plomo -in the Andean foothills and proto-urban level-causes a reactive discourse in the contemporary territoriality of the urban metropolis which subverts the fragile joints of all the different spaces and strata of Santiago City. In this way, Cielo de Serpientes presents a narrative discussion of the segments and status of knowledge and power in a way that debates with the notion of territory and with the forms of cultural and popular knowledge present in it. In this text, space is a lived dimension appropriated by each individual and non-exchangeable for other practices or other dreams.

Key words: The Inca rituals, Andean territory, urban territory, Chilean novel.

La convicción de que vivimos cambios profundos a nivel de realidades de hecho (políticas, económicas, tecnológicas, morales, estéticas, entre otras), asî como en los modos de conocimiento, comprensión e interpretación de ellas, es una cuestión de lo más relevante en nuestra época, siendo muy significativo que tal asunto se manifieste como un pronunciado cuestionamiento a las maneras tradicionales (modernas) de aprehensión de lo real, lo que se ha venido asumiendo con el llamativo título de cambio de paradigmas.

La consecuencia inmediata de esto es el convencimiento de que experimentamos una situación marcadamente crítica, lo que implica la creencia en la inestabilidad de los paradigmas, y que se ilustra en la velocidad con que se van erosionando sus perfiles y promoviendo ya no tal o cual reforma, sino que su sustitución, su reemplazo. De este modo, en el problema paradigmático no solo nos enfrentamos a nuevas ideas acerca de la realidad de los objetos que interesan a la ciencia y, en general, a todo saber, sino que, también, a las nuevas ideas acerca de lo que es el saber o el conocimiento.

\section{Sobre Tiempo, Espacio y Territorio}

De acuerdo con los nuevos paradigmas de la complejidad, el territorio es un ambiente,

\footnotetext{
1 Departamento de Humanidades y Arte, Universidad de Los Lagos, Avda. Fuschlocher 1305, Osorno, Chile. ebarraza@ulagos.cl

2 Centro de Estudios del Desarrollo Local y Regional (CEDER), Universidad de Los Lagos, Lord Cochrane 1056, Osorno, Chile.nvergara@ulagos.cl
} 
un conjunto de procesos que participan de la constitución de la realidad, formando parte de los mundos con que el hombre tiene que afrontar para la creación y realización de sus proyectos; un espacio de intervención, un espacio de conflictos y de resoluciones, pero también de expectativas e incertidumbres, de logros y de fracasos y, en este acontecer, el territorio se presenta como algo a recorrer, a investigar, a defender, a reconocer como propio o como ajeno. Es decir, el territorio es un espacio referido a lo humano, una relación que es estricta correlación y, fundamentalmente, correlación de sentidos, efectivos o presuntos, imaginarios o virtuales. Por lo tanto, el territorio no es solo una porción de tierra -urbana o rural-, sino un escorzo de mundos articulados y situados en una cultura, con todos sus niveles, estratos o subsuelos de sentidos. Cuando el hombre marca o demarca un territorio delimita un locus mayor o menor según la representación y la conciencia que él tenga de los horizontes de sus mundos. De aquí deriva la notoria conexión del territorio con la identidad, personal o colectiva, y su manifestación en la memoria, en la imaginación y en el discurso.

El territorio es, entonces, una de las formas cómo se nos da el espacio, si bien de un modo determinado. Otras formas son el lugar, el paisaje, el sitio, el no lugar, etc. (Augé 2002). Pero el territorio es, primeramente, un espacio vivido como plural en un sentido efectivo o simbólico y siempre será algo relacionado con lo propio, es decir, asegurado como inherente e indesligable de uno mismo, como inherente a un ser y a un estar, al mismo tiempo ${ }^{2}$. En este sentido podemos afirmar que la noción es más significativa que la de paisaje por cuanto esta última refiere más bien a un recorte visual del territorio o, en general, de un lugar o de un espacio.

Y este es el punto más claro, nos parece, en que el tiempo hace su emergencia en el centro de la vitalización del espacio-territorio, historizándolo. Por esto, el espacio no es, en realidad, separable del tiempo: nos situamos y situamos a los otros en este cruce que se nos aparece como encrucijada, efectiva o simbólica, como dilema espacio-temporal. Por esto, también, el territorio se carga de tabúes, rituales, ceremonias, fiestas; sobre todo fiestas (Delgado 2008). Al decir de Foucault (1999), utopías y heterotopías son signos inequívocos de referencias espacio-temporales y no solamente espaciales. Y esto, en todos los planos. También en aquellos planos poéticos, donde los cuerpos, como lugares o paisajes, son recorridos como propios o extraños por quien busca o sigue sus huellas en el tiempo. Y así como sueño e imaginación se corresponden también ruinas y memoria colectiva se co-pertenecen.

Todas las ideologías, grandes o pequeñas, suponen o exigen, $\mathrm{y}$-en esta medida- señalan hacia la territorialidad en cuanto símbolo de la proyección y trascendencia de los espacios en su connotación discursiva mediante metáforas espacio-temporales que van dibujando los contornos de la experiencia vivida, sea como presente, como pasado o como futuro. Por esto, la utopía no solo es un futuro. Está también en los orígenes al que se sueña volver, que se añora y rememora, que se hace un lugar en nuestras emociones y memorias y que nos llama a un rescate del tiempo. Y está, también, en el presente, en las luchas por la recuperación del pasado que permita abrirse camino hacia adelante y que tiene la misión de dar cumplimiento a un destino: metáfora, también, de un vacío que señala hacia un virtual tiempo recobrado, aunque sea solo imaginativamente.

Paradójicamente, el lenguaje hace que el espacio no solo esté en el tiempo, sino que en rigor sea tiempo y, acaso, no sea sino tiempo. Puede ser. La vida cotidiana -ha dicho Giannini (1987)- es lo que nos pasa. $\mathrm{Y}$ el territorio es siempre algo que nos pasa de múltiples maneras. Por esto, las reflexiones precedentes son aplicables a la escritura narrativa del tiempo, el espacio y el territorio que lleva a cabo Antonio Gil en Cielo de serpientes, según expondremos a continuación.

\section{Legados y Territorialidades Andinas}

Más allá de la territorialidad que hace referencia a los Andes y a sus protourbes andinas, desde una perspectiva histórico-geográfica o mítica, el altiplano es, en específico, un "ámbito que integra los ritos y los mitos", un lugar "en que todas las sociedades instalan sus principios más inalterables, los axiomas de los que depende su continuidad y la del universo mismo", un locus donde "pueden encontrarse técnicas destinadas a poner de manifiesto cómo no hay nada en la organización del mundo que no se perciba como susceptible de desintegrarse en cualquier momento para volverse a conformar de nuevo, de otra manera" (Delgado 2008:20). Y el legado de la cordillera de los Andes concierne a un territorio específico en el que concurre un conjunto de procesos que participan de la constitución de la realidad, formando parte de los mundos con que 
el hombre del Altiplano tiene que desafiar para la creación y realización de sus proyectos. Más allá de las sagradas capitales andinas se extiende una extensión prourbana inconmensurable solo limitada por los cuatro puntos cardinales que resultarán convocados con ocasiones de los rituales de altura, por ejemplo. Se trata-como se ha dicho-de un espacio de intervención, de expectativas e incertidumbres y en este acontecer se presenta como algo a recorrer, a reconocer como propio o como ajeno, perteneciente a los dioses solares -encarnados en hombres- $\mathrm{y}$ a los ritos que los perpetúan como tales o que conjuran la adversidad. Es decir, como hemos anticipado, el territorio no es una simple superficie o demarcación física sino que "es" jerárquicamente en su referencia a lo humano, en una relación que más bien es correlación de sentidos, efectivos o presuntos, imaginarios o virtuales. Parafraseando a S. Boissier, diremos que no hay vida humana des-territorializada (Boisier 1996).

Luego de sucesivas novelas de filiación histórica $^{3}$-en las que aborda narrativamente las figuras históricas de Almagro (1992), Gil de Castro (1994), Ercilla (1997)- con Cielo de serpientes Antonio Gil parece "volver a casa", a las dimensiones urbanas de Santiago de Chile estimulado por la ajenidad de tiempo y espacio que provoca en su contemporaneidad y en su locus citadino el hallazgo de un niño sacrificado (hacia 1527) en el cerro El Plomo según los rituales incas de una "poderosa ofrenda" denominada capac cocha (Ceruti 2003; Duviols 1976; Hernández Príncipe 1986) ${ }^{4}$.

Frente a este episodio el novelista asume -en más de un sentido- la actitud referencial de un cronista (periodista/investigador) que mediante un reportaje procura "reconstruir" la historia en el tiempo y en el espacio narrativo. Con este propósito entrevista a los diversos protagonistas, acopia crónicas periodísticas, documentos y escritos de diversa índole y trae al presente la voz de Tanitani (Kauripaxa o Cauri Pacsa), el niño inca a quien hace relatar su peregrinación como víctima propicia destinada a los dioses ${ }^{5}$. Como ha señalado Antonia Viu, en esta novela asistimos a un proceso de "encrucijadas y mediaciones" de tiempo y espacio, por cuanto

El presente del narrador-investigador... ya no se despliega en los faldeos de la cordillera ni en las cumbres en que se realiza el ritual, sino en el territorio que hoy conecta la ciudad globalizada con el espacio profanado de la montaña: el suburbio de Puente Alto (Viu 2010:197).

La itinerancia del narrador hace perceptible que la ciudad es -según describe Delgado- una

realidad delimitable compuesta de estructuras e instituciones sociales, un continente singular en el que es posible dar -como se pretende a veces- con culturas o sociedades que organizan su copresencia a la manera de algo parecido a un mosaico (Delgado 2008:11).

Copresencia temporal y mosaico, espacialidad hecha de fragmentaciones, asonancias y suturas presiden el mundo narrado en Cielo de serpientes. Antonio Gil indaga en el doble registro que se produce entre el tiempo y el mundo precolombino (de sacralidad andina) y el tiempo/espacio contemporáneo de Santiago que el autor focaliza desde una reliquia más allá de su calidad de objeto del pasado. De este modo, Gil articula un dialogismo prehispánico/ chileno más allá de la urbe-tablero trazada por el conquistador, por medio de una actuación verbal en la que el mundo altiplánico preurbano aparece en todo su animismo y sacralidad, en una extensión cultural (transespacial) antes que imperial, cuyas extensas demarcaciones comprenden el trazado del camino del inca, tambos, pucaras, cumbres y lagunas sagradas. Por lo mismo, más allá del territorio colonial hispánico, acotado como un tablero de ajedrez en el que asienta sus bases "la ciudad letrada", administrativa, judicial e intelectual -según describe Ángel Rama (2006)-, Santiago no aparece en esta novela como el prototipo de la ciudad en sinonimia con lo urbano (en términos de urbanización o provisión de servicios básicos para la ciudad). La capital chilena no emerge como "composición espacial definida por la alta densidad poblacional y el asentamiento de un amplio conjunto de construcciones estables, o como una colonia humana densa y heterogénea conformada esencialmente por extraños entre sî" (Delgado 2008:23).

Lo urbano no radica, entonces, en una "espacialidad geométrica, homogénea, unívoca, clara y objetiva" (Delgado 2008:35) propia de la ciudad, en donde el estar de cada cosa se sitúa temporal y espacialmente en un aquí (acá) y en un ahora (ya); o en un allá (después) y en un entonces 
(antes de ahora), de modo que -en cualquier casopareciera que todo aparenta estar siempre en su sitio (Delgado 2008:39). El hallazgo del niño inca en una de las cimas andinas y su comercialización en un almacén de un poblado semiurbano provoca en el aquí y ahora de la metrópoli un discurso reactivo que subvierte las frágiles junturas de los distintos espacios y estamentos que la ciudad se ha dado a la fecha, lo que pone de relieve los compartimentos del saber, el poder y la cultura.

Para efectos de nuestra descripción -que esbozamos de manera preliminar en 2013- en esta novela es posible distinguir una estratificada topografía que circunda la localidad de Puente Alto, la que da cuenta de

un estilo de vida marcado por la proliferación de urdimbres relacionales des-localizadas y precarias en que imperan nexos discordantes, integraciones provisionales antes que las funciones integradas, propias de una sociedad orgánica (Delgado 2008:23).

No se trata de una localización geográfica, sino de visibilizar desde Puente Alto -donde se lleva a cabo la entrevista entre el autor textual y Jaime Ríos- un eje de sentido desde la elocución del relato a partir del cual el lector puede percibir el entorno de un territorio "aterrazado" (al modo inca), en el que se despliegan graduales niveles de significación como los siguientes:

(a) espacios superiores no urbanos (o preurbanos) como lo es la territorialidad de los Apus andinos (desde el pasado y el presente) vivida y transitada por Tanitani hasta su consumación en el cerro El Plomo;

(b) espacios mediadores naturales y precordilleranos propios de las estribaciones, quebradas y roquedales, escasas planicies, reducidos valles y ríos actualizados por el deambular empecinado de los huaqueros o buscadores de reliquias (Gerardo Luis Ríos Barrueto, Guillermo Chacón Carrasco y Jaime Ríos Abarca);

(c) espacios suburbanos (más que periféricos) como el de la localidad de Puente Alto donde vive Jaime Ríos hacia 2007 cuando se celebra la entrevista, o el pueblito de San Alfonso (en el Cajón del Maipo) desde donde se hacen los contactos con el Museo Nacional de Historia Natural (Gil 2008:29) ${ }^{6}$; (d) el enclave urbano-metropolitano de la Quinta Normal, como lugar de intraexilio, de la reclusión de Tanitani, por cuanto allí está situado el Museo Nacional de Historia Natural donde residirá finalmente esta reliquia y será monumentalizada como objeto cultural. Nos referiremos sumariamente a ellos ( $C f r$. Barraza y Vergara 2013:163 y ss.).

\section{El Territorio del Apu: Santuario de Tanitani}

En 1954, un niño inca es arrebatado de su sitio territorial -como protector del valle del Maipo- acotado en la terraza superior del Apu o cerro sagrado. Su presunto rescate (para el saber de otros) lo desplaza desde su locación consagrada en una cumbre (superior) primero hacia un descenso parcial hasta una cueva llamada Piedra Numerada situada a una altura sobre los 3.000 metros. Luego, se efectuará un posterior descenso hacia un territorio (inferior) y hacia un tiempo secular, extemporáneo y ajeno -aledaño del valle precordillerano- donde es exhibido por sus "captores" ante espectadores periféricos que, a lo más, demuestran su asombro o intuyen la magia de la muda cordillera o los ritos de hombres de otros tiempos. En un "despacho de menestras de Olegario Vallejo en San Alfonso, en el Cajón del Maipo"7 transitoriamente, Tanitani es exhibido, pesado, medido y tasado como cualquier otro producto que se muestra y transa en un prosaico almacén de barrio.

Hemos dicho que, en lo fundamental, como espacio, el territorio es un entorno. Pero no un entorno abstracto, aparte e independiente, sino siempre un entorno de alguien, de una colectividad, o de una persona en cuanto pertenece a una colectividad, y tal ocurre en esta novela cuando asistimos a la voz rememorante de Tanitani. Antes de su exhumación por parte de los huaqueros, Tanitani refiere su peregrinación hacia el $A p u$ sagrado y, por esta vía de elocución, el territorio se transparenta como un espacio de la vida plural, colectiva, social o cultural, y no como un mero marco físico donde se localizan las cosas. Es decir, no un espacio ahí, simplemente, aparte, objetivo y suelto, por sí, sino un espacio vivido, plural, lo que expresa que no posee autonomía de quienes se encuentran en él, por cuanto, el estar allí de estos es un hallarse siendo ahí, un encontrarse siendo constructores mancomunados de ese ahí, según 
condiciones que el propio espacio exige, sugiere o suscita. Esto es, habitándolo o rememorándolo, si cabe. En este sentido todo espacio implica una construcción social, cualquiera que sea la figura que adopte. Y el territorio es una de esas formas. Pero el territorio es, a la vez, un espacio vivido, como lo vive Tanitani. El territorio es, entonces, siempre mi espacio o el espacio de los otros, semejantes o distintos de mí o de nosotros, en quienes puedo reconocerme como lo que en esencia soy, así como los otros se reconocen en el suyo. El espacio-territorio es vivido como plural en un sentido efectivo y no abstracto o imaginario. Como plural, el territorio comporta distintos momentos y circunstancias de la vida y es signo inequívoco de valores espirituales diversos, desde lo aparentemente más banal e insignificante. Se trata de una territorialidad -metaurbana, podríamos decir- supuesta en forma indistinta como de todos y de nadie, que atesora desde lo más banal e insignificante hasta lo más profundamente inhabitual y, paradójicamente, más significativo, como ocurre con el espacio ceremonial que suele asimilarse a lo sagrado, pero que no es incompatible con rituales profanos. El territorio es, entonces, identificatorio de lo común y de lo excepcional. Pero siempre propio, es decir, asegurado como no enajenable sino inherente $\mathrm{e}$ indesligable de uno mismo mediante un simbolismo de la territorialidad, como sería el caso del espacio retórico, al decir de Augé (2002).

Esta pertenencia-identidad entre sujeto y territorio es la que expresa el novelista cuando ficcionaliza la historia de Tanitani y nos proporciona la voz de su infancia peregrina. El núcleo espaciotemporal se dinamiza mediante el motivo de un viaje o de una transitoriedad sagrada en ascenso hacia la cordillera que conduce al lugar "donde van las mariposas pilpintu cuando dejamos de verlas" (Gil 2008:12), cuya meta es consumar el ritual para el que ha sido elegido el niño inca ( $C f r$. Barraza y Vergara 2013:164 y ss.).

En su estar en el tiempo y espacio propios, el consagrado niño inca vive en completa armonía con su pueblo y con sus tradiciones y en armonía con la naturaleza, al extremo que -una vez consumado el ritual- terminará fundiéndose con el tiempo y espacio sagrados, según expresa en esta cita

comencé a convertirme en el tiempo mismo de la andada y en la tibieza tímida del sol, y comencé a devenir y a devenir volviéndome la tierra y la rocada que ascendimos, y de pronto se encendieron las estrellas dentro de mí y salió un sol mío y se puso en mí un sol también y vinieron hombres y mujeres a poblar mi pensar como un vasto llano (Gil 2008:53).

Entre la cumbre del cerro sagrado y el cauce del río Mapocho distan más de 5.000 metros de altitud ${ }^{8}$, distancia que desafían permanentemente arrieros y huaqueros. Se trata de una superficie escarpada, abrupta, que -aparte de turistas y andinistas- solo puede animar a quienes como los huaqueros intuyen secretos, misterios y riquezas en sus quebradas y roquedales. Según una nota del novelista (Gil 2008:29), no le son desconocidos episodios que acontecen en estas laderas; tampoco la geografía, las numerosas aldeas, ríos y hondonadas que componen el mapa territorial de este entorno. Menos le es desconocida la protohistoria de un apogeo preliminar en torno a manufactureras de papel, instalaciones militares y circunvalaciones ferroviarias.

Según nuestra perspectiva de lectura, junto con ser un espacio intermedio -en términos de altitud y nivel-, quebradas, planicies, cajones y valles preandinos en las cercanías de San Alfonso actuarían como una "terraza" intermedia porque la próxima sería Puente Alto donde se lleva a cabo la entrevista entre el autor y Jaime Ríos. Tomando en cuenta el lugar desde donde Gil articula este texto, el espacio del "cajón del Maipo" (Gil 2008:29) se reivindicaría por contener un tiempo de la infancia del narrador. Un territorio de la niñez que resulta extinto desde la mirada del presente más inmediato de Jaime Ríos quien siente que ha sufrido las consecuencias de la "desgracia" que significó la profanación del santuario del niño Tanitani (Gil 2008:103). Marginado del protagonismo de la aventura vivida en su niñez (Gil 2008:43), en el 2007, un anciano Jaime Ríos comparte con el novelista su enciclopedia de recortes de diarios (Gil 2008:138) y de recuerdos. Desde un presente precario y, frente a su interlocutor, da sentido a su experiencia de la precordillera como un territorio de sueños y de fracasos, de encantamientos y desencantamientos como aquellos que provoca la leyenda del Tesoro del Gran Inca, sobre la que la novela no entrega mayores antecedentes

Quedé bien aspeado con la vida que he llevado. $Y$ en veces sueño muchas noches 
seguidas con esos desiertos y esos cerros donde nos gastamos la juventud guaqueando (Gil 2008:43).

Por lo mismo, la interlocución entre el novelista y el huaquero provoca un contrapunto entre la percepción de ambos respecto del territorio precordillerano. Para Jaime Ríos ha significado su propio desgaste como resultado de una búsqueda infructuosa

El hombre no está acostumbrado a caminar sobre el cascajo

Eso lo jode y lo envejece a uno. Se le come también hasta la médula de los huesos el frío de la noche, amigo, y la andada por cascajo. Es para mulas el cascajo y para los machos herrados como ya le decía, lo va descoyuntando hasta el alma a uno, vea nada más cómo tengo las rodillas de tanto inclinarme al borde de las tumbas y en la boca de las grutas y socavones para husmear, buscando y rebuscando el gran tesoro del Inca. Ese entierro escurridizo... (Gil 2008:43-44).

Por su parte, el novelista quiere, más bien, reconstituir y evocar por medio de su discurso un estado anterior y natural de tiempo y territorios y situarlos como plenamente vividos por un Viejo Guaquero quien, así, podría recordar

las sendas y los matorrales por donde alguna vez anduvo... Se acordará del olor caprino y leñoso de los montes. Sentirá otra vez el viento de las serranías arrastrando semillas de cardo y arenisca. Y la inmensidad. La anchura enorme acorralada de cerros. Los horizontes aserrados, colmillados de cumbres que se pierden hacia el fondo del pasado, con sus portezuelos, con sus caletones con sus parapetos donde encender el fuego y escuchar las voces y los llantos que trae la noche de la montaña con sus ilusiones y sus ánimas (Gil 2008:124).

Sin embargo, no escapa al novelista el reverso de esta reconstrucción discursiva e ilusoria de vida y territorio, pues, intuye que -desde su vejez- el Guaquero Viejo creía ver los fantasmas de las vastas llanuras por donde anduvo alguna vez, las infinitas pampas saladas por donde perdió los pasos y quemó las suelas de los calamorros hacia el horizonte de cal viva, sosa, caliche y roca metamórfica, más allá de los inmensos campos de litio que se hunden en lontananza al fondo de las imposibles escolleras de galena que dan paso a aquellos parajes infernales de donde no se vuelve, sembrados de antiguos huesos (Gil 2008:43).

No obstante, la ensoñación del novelista no logra suplir el presente desde el que recuerda Jaime Ríos. El Viejo Guaquero está situado en Puente Alto en un territorio semirrural y suburbano que -como un andamio- conecta sueños escurridizos que lo atrapaban desde el Apu para deambular tras el inhallable Tesoro del Gran Inca (Gil 2008:42) y exorcizar el degradado límite de la periferia

Los suburbios resucitan a sus polvaredas, a sus perros flacos, a su rumor miserable donde el viejo cree ver y escuchar todavía, las infinitas pampas y cañadones por donde el viento sopla, arrastrando semillas y cenizas y agua nieve y promesas. Los parajes sin fin por donde vino, andándose la vida entera, solo para dar con sus huesos en este rincón, frente a una ventana rota hacia unos días que no le dicen nada (Gil 2008:127).

Y desde este pobre y anónimo rincón, el novelista permite que Jaime Ríos "encare el vacío de lo que nunca fue y donde él cree adivinar todavía pampas surcadas por trenes humeantes senderos resecos, guacas, derroteros y cerros trajinados por esos mismos pies que ahora titubean en el linóleo" (Gil 2008:133).

\section{Puente Alto: la periferia urbana}

En correspondencia con nuestro punto de vista, Puente Alto (sea en 1954 o en 2007, cuando ocurre la entrevista entre el novelista y el huaquero) puede ser visibilizada como una terraza independiente de aquella del "cajón cordillerano" que es propuesta como la cara visible del "inframundo" o el Mundo de Abajo, en el que la novela ubica a Tanitani en su 
último fragmento y evidencia las consecuencias de que el valle haya perdido su figura tutelar. Es el lugar desde donde el investigador y novelista se pregunta por Tanitani y enciende una fogata imaginaria para orientarlo en dicho inframundo y provocar que el fuego alimente "fábulas de niño en la oscuridad" (Gil 2008:141, 163).

Ofrendado al Ари o Guardián Sagrado -conocido hoy como cerro El Plomo- Tanitani experimenta el trauma de la separación del mundo de los suyos $\mathrm{y}$ de su entorno territorial y se torna un peregrino entre ambos mundos (Barraza 2009): el de sus abuelos y el de los dioses. A su vez, la profanación de que fue víctima su tumba (la "apacheta") por hombres de otro tiempo y de otra cultura genera otra pérdida: la de su condición sagrada que lo incapacita para proteger a su pueblo originario y dialogar con los suyos

Awichu, Awichu abuelo. ¿Dónde te ocultas que ya no puedo hallarte? ¿Soy Tanitani? ¿Qué otra cosa soy ahora? ¿En qué me he convertido? Mírame, me traigo perdido por estas tierras oscuras y hace frío, mucho. Y no veo el ayllu ni sus humaredas en la mañana (Gil 2008:162).

La inserción en el mundo prosaico de los huaqueros traduce una mudez definitiva de Tanitani. El tiempo-espacio de los buscadores de tesoros es menos que mediocre y no favorece dialogismo alguno? .

Por cierto, Puente Alto es el suburbio -técnicamente, una conurbanización-, vale decir, lo urbano reducido a la subalternidad, a una subordinada periferia que tiende al centro de la metrópoli cuando, por el contrario, la experiencia de los huaqueros es subir hacia los territorios cordilleranos y arrancarles sus enigmáticos secretos ${ }^{10}$. Como intuye Antonia Viu, en la novela, la importancia del emporio de menestras "radica en que, en tanto espacio, constituye un lugar de enfrentamiento de dispares fuerzas y saberes arquetípicas" (Viu 2010:196). En ese almacén ocurre una transacción primaria que, con posterioridad, se verificará en el Museo Nacional de Historia Natural, hecho que hace patente Luis Ríos en sus memorias póstumas publicadas el 2009. Se trata de un espacio no equidistante ni de las cumbres ni del ritual. Tampoco estimamos que desde allí se conecte equitativamente "la ciudad globalizada con el espacio profanado de la montaña", como plantea Viu (2010:197). El suburbio de Puente Alto, como lo denomina el novelista en varias ocasiones (Gil 2008: 41, 113, 126, 141) es el locus donde se consuma una transacción que supedita lo sagrado a lo profano, en un trato que tampoco valora el autorizado conocimiento territorial y la cultura popular que poseen los huaqueros, según percibe el novelista cuando Jaime Ríos le confiesa

-Aquí está todo lo que me queda de toda esa famosa aventura, amigo- dice Guaquero Viejo con un resabio amargo en la voz temblorosa. Y este collar.

Extiende un puñado de chaquiras y turquesas deshiladas.

El collar lo traía puesto el niño, y yo me lo guardé y lo he tenido por ahí todos estos años (Gil 2008:83-84) ${ }^{11}$.

\section{La ciudad y el museo}

La contraparte de Puente Alto es el Museo Nacional de Historia Natural de la Quinta Normal, en Santiago de Chile. La historia del niño del cerro El Plomo que recoge el novelista muestra al Museo como un espacio urbano-céntrico que integra un discurso heterogéneo de crónicas, pruebas científicas y seudocientíficas, vidas prosaicas -interesadas más que ritualizadas-que enmascaran un "rescate" del pasado, haciéndolo "descender" de su condición sagrada. La urbe está dinamizada por un movimiento inverso $^{12}$ al de los sacerdotes venidos del Cusco, dinamismo que lleva consigo la profanación, por cuanto se afirma que con la manipulación del niño inca "el valle central de Chile ha quedado por fin completamente desprotegido" (Gil 2008:84). Esta asonancia de discursos -más que hibridación- la anticipa Antonio Gil en la apertura de esta novela, a partir de la glosa de un informe de la Dra. Grete Mostny publicado en 1957 que consta igualmente en un folleto promocional que el Museo distribuye a sus visitantes. Mostny se refiere -con fría erudición-a los restos de la momia del cerro El Plomo "rescatada" de su sitio ceremonial. Describe minuciosamente el vestuario y los adornos del niño. A lo anterior se sumará el bisturí implacable de los informes forenses (Gil 2008:31), tasaciones, fraudes, fechamientos, diagnósticos y estudios de laboratorio, como los de Rodríguez et al. (2011) o de Sanhueza (2005), análisis mineralógicos del sitio sagrado, todo ello resulta insuficiente para destrabar la escritura de 
estos quipus que -según el novelista- cifran el secreto de la "materia muda", ese "silencio de los átomos" de tiempos y espacios cohesionados, privilegio concedido a un niño inca, situado en el ámbito de lo insondable, por cuanto

entre ese y este mundo está el Niño profanado de El Plomo. Entre su apacheta demolida a patadas y el enigma de lo que baja y baja y baja por el valle, con la tibieza de cada mañana, dormía su grandeza escondida en el minúsculo gesto fetal, tan inmenso como un imperio que apunta los ojos hacia abajo. Hacia un universo inconcebible de lo infinitamente pequeño (Gil 2008:131-132).

Mediante una manifiesta alternancia discursiva y temporal, la novela construye un collage de segmentos textuales superpuestos y relativamente autónomos, de manera que perfectamente los ciclos narrativos prehispánicos y aquellos de la cultura nacional se pueden leer por separado. En el fondo, el lector de esta novela debe "desanudar" los trece "nudos" -o capítulos de esta novela- tal como los quipucamayoc incas destrenzaban la secreta escritura de los quipus, en un acto en el que, según el novelista, se "lee tocando la enseñanza más vieja, dura y escondida de todas" (Gil 2008:18).

Esta instantaneidad entre oralidad, referente y lectura, propia de culturas que viven como "escribiendo en el aire", según postula Cornejo Polar (1994), no es la misma que se observa en la letra impresa de los diarios y revistas científicas y pseudocientíficas de la época, como Vea (Gil 2008:138); La República (Gil 2008:159); National Geographic, Siglo Cero (Gil 2008:160); Revista Chilena de Radiología (Gil 2008:61), en las cuales la "cultura arqueológica y museográfica" y el patrimonio de discursos académicos de investigadores, radiólogos o de antropólogos, coexiste con los intereses diversos de cófrades esotéricos, seudo-investigadores (disfrazados de coleccionistas privados), traficantes y "huaqueros" o buscadores de tumbas y restos precolombinos (Cfr. Barraza y Vergara 2013:166 y ss.).

En consecuencia, según anticipáramos (Barraza y Vergara 2013:169), Cielo de serpientes ilustra que el territorio, y, en particular, la ciudad, lo urbano en cuanto espacio y tiempo vividos, encuentra su posibilidad de realización en el relato, por cuanto el acto de narrar deviene en una práctica discursiva en que el territorio se dice; esto es, se inscribe en el lenguaje, se abre camino por y mediante el decir.

En particular, según Antonia Viu, la cordillera andina "Más que una frontera infranqueable respecto de la región dentro de la que Chile se inserta, aparece como un territorio poroso desde el que es posible articular nuevas formas de pertenencia... desde imaginarios contradictoria y heterogéneamente compartidos" (Viu 2013:155).

\section{Para Conclusiones: el Novelista y el Huaquero}

De la conquista de Chile por parte del Imperio Inca solo se tienen genéricas referencias. Estas se observan en el léxico del español en Chile, en algunas toponimias, en los vestigios del "camino del Inca", aparte de otros signos monumentales como los tambos, pucaras, huacas y el cultivo en terrazas. Según Diego de Rosales en su Histórica Relación del Reino de Chile. Flandes Indiano (1674?), la invasión inca se habría producido hacia 1425 , luego de las campañas de los Incas Huáscar y Huayna Cápac. Más allá de antropólogos e historiadores, en esta novela Antonio Gil indaga y actualiza la presencia de los incas a partir de sus ritos religiosos, funerarios y mágicos, entre los que se cuenta la tradición de sacrificar-como máxima ofrenda-a una pareja de niños en las cumbres más elevadas de los Andes, para que desde allí (como en hibernación) protejan a los habitantes de los valles cercanos.

"Nada puede salir mal en el ayllu que tutela" (Gil 2008:94) -reflexiona el narrador de Cielo de Serpientes, situándose en el locus del espacio protourbano- y, por esta vía, el novelista media entre el tiempo-espacio de la historia y el tiempoespacio del lector de novelas. Enlaza, así, los protoespacios andinos y "aterrazados" -abiertos a los cuatros puntos cardinales- con la persistencia de la memoria del ritual en los espacios urbanos de la ciudad occidentalizada, construida a semejanza de las metrópolis del conquistador con los respectivos lugares del poder político, sus enclaves culturales y sus estratificaciones periféricas, semiurbanas, conurbanas, semirrurales y precordilleranas, en donde los sujetos se reconocen por los hábitos de sus respectivos saberes operantes. La mirada de Antonio Gil hacia el mundo inca remite hacia la herida colonial de la que habla Mignolo (2007), hacia ese sentimiento de inferioridad con que son 
degradadas las culturas originarias por imposición de esa hegemonía eurocéntrica que lleva consigo el conquistador y, posteriormente, la Nación. Un sentimiento de inferioridad que afecta a la relación entre los individuos y sus espacios originarios. Tanitani es apartado de su territorio originario del Cuzco para cumplir con el ceremonial en un espacio ajeno como es el cerro El Plomo, territorio que su pueblo proclama como una cumbre sagrada, protourbana, para tutelar desde la altura otros valles y otros hombres como los de Chile. Tal tránsito y ajenidad hace de Tanitani un peregrino de tiempo y espacio, más aún cuando sea exhumado desde la cima del Apu y luego se le haga descender hasta la periferia urbana. La pérdida de su condición sagrada lo relega a una vida errante que lo incapacita para proteger a su pueblo, según se desprende de esta cita

me traigo perdido por estas tierras oscuras y hace frío, mucho. Y no veo el ayllu ni sus humaredas en la mañana. Ya no le sueño el resollar brumoso y asustado a la alpaca lechona, ni la dentición del maíz, ni el florar celeste de la papa en los terrados puedo soñarles, y fue eso lo que me pidieron con cánticos y rogativas en el Monte. Vengo solo por el arbolar quemado, sin agua, sin lumbre, sin nada que llevarme a la boca. Jatvn mama, ven a buscarme. Si todavía soy Cauri Pacsa, Hatucha, te lo pido llorando (Gil 2008:162).

El peregrinaje de Tanitani no difiere en mucho del que experimenta Jaime Ríos, tan niño como el niño inca cuando ascendió el cerro El Plomo. Jaime también ha quedado al margen de la historia. A diferencia del legendario Guillermo Chacón, su nombre no lo registran los periódicos ni ha escrito memoria alguna como su tío Luis. Ha crecido y ha envejecido recorriendo los espacios no urbanos sino precordilleranos tras míticos tesoros incas para terminar recluido y decepcionado en la base periférica y semiurbana de la cordillera a la que no puede volver.

Por lo mismo, la presencia del pasado de los incas y sus rituales sagrados resultan desbordados en esta novela por el Chile de mediados del siglo XX pero su reivindicación no resulta satisfactoria cuando la momia de un niño inca $-y$ la memoria de ese pasado-queda recluida en un museo metropolitano como pieza arqueológica. El episodio de Tanitani lleva consigo no solo la narratividad de ese pasado sino, a la par, su espacialización, su topos, puesto que ese ceremonial del ayer precolombino conserva y reclama su referencia territorial en el apu o cerro sagrado que preside el valle de Santiago desde siempre, al modo de una "memoria o escritura de piedra", como aquella que se presenta a la vista en los cerros, rocas, petroglifos y geoglifos que abundan en el territorio-espacio de los Andes. Como señala Martin Lienhard, "la memoria oral dispone de mecanismos para archivar formas o contenidos de discursos antiguos cuya relevancia, en términos del presente vivido por los oyentes, puede resultar escasa" (Lienhard 2004:11). Desde una pétrea y mágica grafía, tales mecanismos suplen la escritura eurocéntrica como refiere un imaginario andino. En la proto-urbe, se recuerda

Ellos enviaban cartas desde el Cusco hasta Cajamarca, en hondas. Con un hondazo la piedra corría ardiendo. En esa piedra caminaban unas letras inscritas. Cómo harían las letras en esas piedras. No era como ahora escriben en papeles, ellos escribían en piedras. Entonces la piedra iba ardiendo, volando por lo alto. Uno hondeaba y la piedra caminaba por los aires adonde era destinada y ardiendo llegaba. Las letras de esa piedra leían (Escalante y Valderrama 1997:125).

Tales son las distancias y los modos de vivir -y de poner por escrito- los mundos urbanos y protourbanos.

En suma, resulta evidente coincidir en que la memoria oral de los pueblos precolombinos ha sido escrita por los descubridores, conquistadores y evangelizadores de este continente. Como ilustra Tanitani, la memoria oral es propia de pueblos que no requieren la grafía, de la palabra vista, sino de la palabra dicha y oída, esa que no responde a los vínculos discursivos de la memoria escrita (Barraza 2004). Sin embargo, como ha señalado Cornejo Polar, cabe suponer "un punto en el que la oralidad y la escritura no solamente marcan sus diferencias extremas sino que hacen evidente su mutua ajenidad y recíproca y agresiva repulsión", cuando no diferencias específicas (Cornejo Polar 1994:26-27). Por lo pronto, según Perla Petric, la memoria precolombina "no solo retiene una mitología tradicional"... sino que su finalidad es "crear una representación", es decir, 
"una versión de la realidad"... para ("interpretar"), dar sentido a lo existente... Se trata de "interpretar" para... establecer "una dependencia inamovible entre los hombres y la (s) divinidades"... "para justificar o provocar hábitos de comportamiento" (Petric 2004:56). Se trata, en síntesis, de una expectativa de vida, propia del mundo andino, por completo ajena al prosaísmo, al cálculo y a una cultura de saberes estereotipados respecto de nuestros inarmónicos orígenes, según pone de relieve Antonio Gil en esta novela en la que reitera su calidad de genuino narrador para dirigir su mirada hacia la vida en su cotidianeidad, en el cada día y en la complejidad de sus basamentos histórico-espaciales. Según hemos anticipado más arriba, según las estratificaciones temporo-espaciales y de saberes que percibimos en esta novela, el espacio metropolitano emerge, más bien, en proporción a lo urbano entendido por Delgado como "un estilo de vida marcado por la proliferación de urdimbres relacionales des-localizadas y precarias en que imperan nexos discordantes, integraciones provisionales antes que las funciones integradas, propias de una sociedad orgánica" (Delgado 2008:23).

Como propone Viu, en Cielo de Serpientes se advierten "las significaciones culturales que de forma clandestina [e intersticial] siguen circulando a pesar de las negociaciones históricas consumadas en el proceso de construir la nación. La cordillera, en este contexto, es el territorio del delirio, de lo marginado, de los intercambios que resultan amenazantes" (Viu 2013:155).

Agradecimientos: la nota 8 se redactó a partir de los aportes de los evaluadores de este artículo, a quienes agradecemos sus valiosas sugerencias.

\section{Referencias Citadas}

Augé, M. 1998. Antropología de los mundos contemporáneos. Gedisa, Barcelona.

Augé, M. 2002. Los No Lugares. Espacios del Anonimato. Gedisa, Barcelona.

Augé, M. 2004 ¿Por Qué Vivimos? Gedisa, Barcelona.

Barraza, E. 2004. De La Araucana a Butamalón. Anejos Estudios Filológicos 17, Valdivia.

Barraza, E. 2009. Antonio Gil. Cielo de Serpientes. Alpha 29:322-325.

Barraza, E. y N. Vergara 2013. Cielo de serpientes de Antonio Gil: escritura de tiempo y espacio. En Territorios del Tiempo. Historia, Escritura e Imaginarios en la Narrativa de Antonio Gil, editado por A. Viu y P. García, pp. 159-172. DIBAM/ Universidad Adolfo Ibáñez, Santiago.

Baudrillard, J. 1978. Cultura y Simulacro. Kairós, Barcelona.

Boisier, S. 1996. Modernidad y Territorio. Cuadernos del ILPES, Santiago.

Castoriadis, C. 2005. Los Dominios del Hombre. Gedisa, Barcelona.

Castoriadis, C. 2007. La Institución Imaginaria de la Sociedad. Tusquets, Buenos Aires.

Ceruti, M.C. 2003. Santuarios de altura en la región de la Laguna Brava (Provincia de La Rioja, Nor-Oeste Argentino). Chungara Revista de Antropología Chilena 35:233-252.

Certeau de, M. 1999. La Cultura en Plural. Nueva Visión, Buenos Aires.

Certeau de, M. 2000. La Invención de lo Cotidiano 1. Artes de Hacer. Universidad Iberoamericana, México, DF.

Certeau de, M. 2007. Historia y Psicoanálisis. Entre Ciencia y Ficción. Universidad Iberoamericana, México, DF.

Cornejo Polar, A. 1994. Escribir en el Aire. Horizonte, Lima.
Delgado, M. 2008. El Animal Público. Hacia una Antropología de los Espacios Urbanos. Anagrama, Barcelona.

Durand, G. 1971. La Imaginación Simbólica. Amorrortu, Buenos Aires.

Durand, G. 2003. Mito y Sociedades. Introducción a la Metodología. Biblos, Buenos Aires.

Duviols, P. 1976. La capacocha. Mecanismos y función del sacrificio humano, su proyección geométrica, su papel en la política integradora y en la economía redistributiva del Tawantinsuyo. Allpanchis Puturinqa 9:11-57.

Eliade, M. 1968. Mito y Realidad. Guadarrama, Madrid.

Eliade, M. 2001. Mitos, Sueños y Misterios. Kairós, Barcelona.

Escalante, C. y R. Valderrama 1997. La Doncella Sacrificada Mitos del Valle del Colca. Edición bilingüe quechua y castellano. Prólogo de Martin Lienhard. Universidad de San Agustín. Lima/ Instituto Francés de Estudios Andinos, Arequipa.

Foucault, M. 1999. Los espacios otros. En Estética, Ética y Hermenéutica. Obras Esenciales, editado por M. Foucault, vol. III, pp. 431-441. Paidós, Buenos Aires.

Gálvez del Valle, S. (dir.) 2008. Puente Alto Siglo XX. Retrospectiva fotográfica (1892-2002). Documentación Histórica y Textos de Luis Alegría Licuime y Evelyn Riquelme Fernandois. Edición del Municipio de Puente Alto, Puente Alto.

Giannini, H. 1987. La Reflexión Cotidiana. Universitaria, Santiago.

Giannini, H. 2007. La Metafísica eres Tú.Una Reflexión sobre la Intersubjetividad. Catalonia, Santiago.

Gil, A. 1992. Hijo de Mí. Editorial Los Andes, Santiago.

Gil, A. 1994. Cosa Mentale. Editorial Los Andes, Santiago.

Gil, A. 1997. Mezquina Memoria. Editorial Cuarto Propio, Santiago. 
Gil, A. 2004. Las Playas del Otro Mundo. Seix Barral, Santiago. Gil, A. 2008. Cielo de Serpientes. Seix Barral, Santiago.

Hernández Príncipe, R. 1986. Idolatría del pueblo de Ocros, cabeza desta comunidad. En Cultura Andina y Represión, editado por P. Duviols, pp. 442-448. Centro de Estudios Rurales Andinos Bartolomé de las Casas, Cusco.

Hidalgo Dattwyler, R., T. Errázuriz Infante y R. Booth Pinochet 2005. Las viviendas de la beneficencia católica en Santiago: Instituciones constructoras y efectos urbanos (1890-1920). Revista Historia 38:327-360.

Lienhard, M. 2004. Huellas del pasado remoto en las tradiciones orales indígenas y afroamericanas. América, Cahiers $d u$ CRICCAL 31:9-17.

Maffesoli, M. 2004. El Tiempo de las Tribus. Siglo XXI, México DF.

Morin, E. 2003. Introducción al Pensamiento Complejo. Gedisa, Barcelona.

Mignolo, W. 2007. La idea de América Latina. La Herida Colonial y la Opción Decolonial. Gedisa, Barcelona.

Mostny, G. 1957-1959. La momia del cerro El Plomo. Boletín del Museo Nacional de Historia Natural. Tomo XXVII, pp. 13122. Museo Nacional de Historia Natural, Santiago.

Ortega y Gasset, J. 1962. El Hombre y la Gente. Revista de Occidente, Madrid.

Petric, P. 2004. Memoria occidental y memoria amerindia. América, Cahiers du CRICCAL 32:55-61.

Rama, Á. 2006. La Ciudad Letrada. Siglo XXI, México DF.

Ricoeur, P. 2004. Tiempo y Narración. Siglo XXI, México, DF.

Ricoeur, P. 2010. La Memoria, la Historia, el Olvido. F.C.E., México DF.
Ríos Barrueto, L. 2009. El Niño Inca. La Verdadera Historia del Niño del Cerro El Plomo. Pehuén, Santiago.

Rodríguez, H., I. Noemí, J.L. Cerva, O. Espinoza-Navarro, M.E. Castro y M. Castro 2011. Análisis paleoparasitológico de la musculatura esquelética de la momia del cerro El Plomo, Chile: Trichinella sp. Chungara Revista de Antropología Chilena 43:581-588.

Rosales, D. de 1989. Historia General del Reino de Chile. Flandes Indiano. Andrés Bello, Santiago.

Sanhueza, Á. 2005. Paleoradiografía: Estudio imagenológico del niño del Cerro El Plomo. Revista Chilena de Radiografía 11:184:190.

Vattimo, G. 1990. El Fin de la Modernidad. Gedisa, Barcelona.

Vattimo, G. 1996. La Sociedad Transparente. Paidós Ibérica, Barcelona.

Vergara, N. 2007. Hombres y entornos. Notas para una metafísica del territorio. Alpha 25:227-236.

Vergara, N. 2009. Complejidad, espacio, tiempo e interpretación. Notas para una hermenéutica del territorio. Alpha 28:233-244.

Vergara, N. 2010. Saberes y entornos: Notas para una epistemología del territorio. Alpha 31:163-174.

Viu, A. 2010. De encrucijadas y mediaciones: Cielo de serpientes de Antonio Gil. Anales de Literatura Chilena 14:193-204.

Viu, A. 2013. La cordillera de los Andes como frontera: Cosa mentale y Cielo de serpientes. En Territorios del Tiempo. Historia, Escritura e Imaginarios en la Narrativa de Antonio Gil, editado por A. Viu y P. García, pp. 139-157. DIBAM/ Universidad Adolfo Ibáñez, Santiago.

Viu, A. y P. García (eds.) 2013. Territorios del Tiempo. Historia, Escritura e Imaginarios en la Narrativa de Antonio Gil. DIBAM/ Universidad Adolfo Ibáñez, Santiago.

\section{Notas}

1 Este trabajo integra el estado de avance de los Proyectos Fondecyt N ${ }^{\circ} 1120693$ "Texto/Nación. La novela chilena de filiación histórica (siglos XIX y XX)" y Fondecyt $\mathrm{N}^{\circ}$ 1120574: "Cotidianeidad, complejidad, imaginarios. Aproximaciones teóricas para la construcción de una hermenéutica del espacio concebida como hermenéutica dialógica territorial".

2 Hecho que se pone de relieve en el caso de transhumancias y nomadías. El sentimiento del nómada es un ejemplo muy claro en la actualidad. También lo es el de quien ha perdido el territorio por efectos del exilio. Emigrantes o inmigrantes y exiliados llevan consigo parte de lo que han sido, así como también dejan ahí parte de lo que es suyo. Del mismo modo aquellos que sienten que su territorio les ha sido usurpado y que confían en poder recuperarlo alguna vez, como es el caso de algunos pueblos indígenas en la actualidad.

3 Entre las novelas históricas de Antonio Gil se cuentan: Hijo de mí (1992), Cosa Mentale (1994), Mezquina memoria (1997), Las playas del otro mundo (2004). Cfr. Barraza (2004), Viu y García (2013).

4 "Los rituales de altura" han sido estudiados por destacados especialistas. Para los efectos de este artículo nos limitamos a señalar que este ceremonial se efectuaba cada cuatro años en el Cusco, preferentemente para la fiesta del Inti Raymi o con motivo de catástrofes, o del ascenso o del fallecimiento de un Inca. Un informativo del Museo Nacional de Historia Natural remite a un informe de Rodrigo Hernández Príncipe efectuado hacia 1662 luego de su visita a San Idelfonso de Recuay en calidad de "extirpador de idolatrías". Allí aparece el nombre de Cauri Pacsa, similar al de Kauripaxa o Cauri Pacssa de Cielo de serpientes. Cfr. Hernández Príncipe 1986 [1621] "Idolatría del pueblo de Ocros, cabeza desta comunidad”, en Duviols 1976.

5 Para un desarrollo preliminar de esta perspectiva, $C f r$. Barraza y Vergara 2013.

6 Citaremos la edición de 2008 de la obra de Antonio Gil, colocando entre paréntesis el número de la página a la que se hace referencia.

7 Según el novelista, su abuelo materno, Primitivo Meneses, le habría relatado este episodio del niño Inca (Gil 2008:29). El autor revela, también, que Graciela Martínez y Rosario Jaque quienes aparecen contemplando la momia en San Alfonso son su abuela y la consuegra de la anterior (Gil 2008:36). Cfr. Viu y García 2013. 
8 Respecto del escenario dado por el novelista, las precisiones geográficas indican que el cerro El Plomo se encuentra en la cuenca del río Mapocho. Es un cerro que puede apreciarse desde muchos lugares de la cuenca del río Mapocho y de Santiago, aunque no desde Puente Alto, pues, allí aparece tapado por otros cordones de cerros (la visibilidad del Apu es una cuestión capital del Inka en la construcción de sus territorios simbólicos). El glacial de El Plomo forma inicialmente al río Olivares, afluente principal del río Colorado, que junto a las aguas del río Cepo terminarán sumándose al río Maipo. A los pies de El Plomo también nace el estero Molina, que al juntarse con el estero Yerba Loca forma el río Mapocho. Históricamente, los arrieros que encuentran al niño inca vivían en Los Maitenes, poblado interior del río Colorado. Sus testimonios han sido novelados por Antonio Gil y constan en un documental de TV. Finalmente, las alturas correspondientes del entorno son cerro El Plomo, 5.300 m; Plaza de Armas, 520 m; Puente Alto, 700 m; Los Maitenes, 1.180 m.

9 Es indudable que la novela no pretende llevar a cabo una "épica de los huaqueros del cerro El Plomo". Sin embargo, el ahora de ellos lo grafica Luis Ríos en sus memorias: "El tiempo transcurría como un suplicio. Les parecía que el mundo se había detenido arrastrando calamidades y miserias, hecho que afectaba gravemente a los primos. Así pasó cerca de un año, sin nada fijo para hacer, solo vaguedades sin importancia" (Ríos Barrueto 2009:20).
10 Puente Alto muestra paulatinamente la invasión del territorio rural por una dinámica urbana, en donde la ciudad no se ciñe a límites. Finalizando el siglo XIX, la cesión de predios por parte de vitivinicultores como Melchor Concha y Toro, Ismael Tocornal, José Luis Coo - guiados por un sentido cristiano para dotar de vivienda a los trabajadores-al promediar el siglo XX dio paso a una liberalización del mercado del suelo y a demandas de reivindicación social mediante procedimientos como "ahorro popular para la casa propia", la "operación sitio", "erradicaciones de campamentos". Tales procesos, presentados como una "política de vivienda social para la clase obrera", traducen una institucionalización de la segregación social que la metrópoli ejerce sobre su periferia suburbana (Cfr. Hidalgo Dattwyler et al. 2005).

11 Todo parece indicar que tampoco queda memoria alguna de "esa famosa aventura" entre los puentealtinos. La "retrospectiva fotográfica" (1892-2002) editada por el municipio no contempla mención alguna al episodio del cerro El Plomo. Cfr. Gálvez del Valle (2008).

12 La comuna de Quinta Normal no es ajena a un proceso de pérdida de su condición de eje cultural y de descentramiento urbano que la ha ido situando a la zaga de los nuevos centros urbanos de Santiago, como Providencia, Vitacura o Las Condes, por ejemplo. 